\title{
Effects of injectable contraceptives on intraocular pressure among women of child bearing age
}

\author{
Precious N. Uwagboe ${ }^{1 *}$, Charles U. Uwagboe ${ }^{2}$, Chioma R. Mba ${ }^{1}$
}

\author{
${ }^{1}$ Department of Optometry, University of Benin, Benin City, Edo state, Nigeria \\ ${ }^{2}$ Department of obstetrics and Gynecology, University of Benin Teaching Hospital, Benin City, Edo State, Nigeria
}

Received: 03 December 2020

Accepted: 05 January 2021

*Correspondence:

Dr. Precious N. Uwagboe,

E-mail: precious.uwagboe@uniben.edu

Copyright: (C) the author(s), publisher and licensee Medip Academy. This is an open-access article distributed under the terms of the Creative Commons Attribution Non-Commercial License, which permits unrestricted non-commercial use, distribution, and reproduction in any medium, provided the original work is properly cited.

\section{ABSTRACT}

Background: The presence of female sex hormones has been linked to variation in intraocular pressure. Numerous studies have revealed that these hormones exert neuroprotective effect and a vascular effect on intraocular pressure regulation. This study was to determine the effect of injectable contraceptives on intraocular pressure in women of child bearing age.

Methods: It was a cross-sectional study, carried out at the University of Benin Teaching Hospital involving 85 healthy Nigerian women of child bearing age (20-50 years). The women were divided into two groups 20-35 years (Mean age was 29.66 \pm 3.43 ) and 36-50 years (Mean age 40.66 \pm 4.41 ). A brief case history was conducted to gain information on their personal data, oculo-visual history and general health. Intraocular pressure (IOP) was measured at baseline and two months after injectable contraceptive.

Results: There was no statistical significant difference in the IOP reading at baseline and after injectable contraceptives among women in group 20-35 ( $\mathrm{p}=0.819)$, whereas women in group 36-50 years showed a Statistical significant difference in their IOP at baseline and after injectable contraceptives $(\mathrm{p}=0.049)$.

Conclusions: Injectable contraceptives have significant effect on IOP of healthy women of childbearing age. Further studies involving a larger sample should be conducted over a long duration in order to achieve a better generalization of the findings on this subject matter.

Keywords: Estrogen, Glaucoma, Intraocular pressure, Injectable contraceptives, Progestogen

\section{INTRODUCTION}

The eye is a target organ for sex hormones. There is a growing observations that sex steroid receptors mRNAs exist in a variety of ocular tissues, such as the lacrimal and meibomain glands, the bulbar and palpebral conjunctiva, the corneal surface, the ciliary body of the lens and the chorio-retinal complex. ${ }^{1}$ It has been suggested that these receptors in the eye might be target sites for androgens, estrogen and progestin; and that these sites might also be susceptible to administered topical and systemic hormonal contraceptives. A number of hormones are known to affect intra ocular pressure
(IOP). ${ }^{2}$ Of these, the female sex hormones are the predominant one to cause variation in IOP. These sex hormones, however seem to exert a neuroprotective effect, a vascular effect, an IOP regulation effect and a support action against lamina cribosa. ${ }^{3}$ When present at sufficient levels, progesterone, a glucocorticoid receptor antagonist, has been reported to increase aqueous outflow, ultimately reducing the IOP. ${ }^{4}$ Glucocorticoid receptors are expressed in the outflow apparatus; thus, their inhibition decreases the $\mathrm{IOP}^{4}$ Injectable contraceptives are exogenous hormones administered intramuscularly with aim of preventing pregnancy. It has been estimated that about 16 million women worldwide 
use injectable contraceptive. ${ }^{5}$ The vasoactive properties of these hormones has been postulated to help combat ischemic changes seen in glaucoma. Multiple studies have confirmed significant reduction in IOP among women on injectable contraceptives than women not taking these form of contraceptives. ${ }^{6-9}$ Estrogen may work to reduce IOP via a different mechanism which include causing a decrease in aqueous production and episcleral venous pressure or by increasing aqueous humour outflow. ${ }^{10}$ Increase in sex hormone seen during pregnancy also lead to reduction in IOP, and most remarkable reduction has been observed also in twin pregnancies than in women with singleton pregnancies. ${ }^{11}$ This is attributed to an increase in levels of estrogen and progesterone. ${ }^{11}$ The observed reduction in IOP may be due to increase outflow facility and decrease episcleral venous pressure. ${ }^{12,13}$ So elevated levels of progesterone during pregnancy may block the ocular hypertensive effect of endogenous corticosteroids. However this was not so in a study conducted on lions as a higher IOP was noticed in luteal lionesses than in non-luteal lionesses, associating elevated progesterone level with increase IOP. ${ }^{14}$ Studies have revealed that women on contraceptives for three or more years are more likely to develop glaucoma and estrogen and progesterone has also been known to cause a decrease in intraocular pressure by influencing outflow facility. ${ }^{15}$ These controversies prompted this study aimed at investigating the effect of injectable contraceptives on intraocular pressure of women within child bearing ages.

\section{METHODS}

The study was a cross-sectional study carried out at the family planning unit of the Department of Obstetrics and Gynaecology, University of Benin Teaching Hospital (UBTH), Benin City, Nigeria. Convenience sampling technique was used for the selection of subjects. The participants were Eighty-five (85) healthy women of child bearing age within the age bracket of 20-50 years, who were attending the family planning clinic of UBTH. All participants were Nigerians living in Edo and Delta Sate. Informed and verbal consent were obtained from each participants and also ethical approval from the ethics committee of UBTH. The study was conducted in accordance with the tenants of the declaration of Helsinki. The women were shared into two groups of 2035 years and 36-50 years. A brief case history was obtained from each subject. The subjects' ocular and general health history were obtained. Visual acuity test was carried out using the standard snellen's chart, external eye examination was carried out, using the slit lamp biomicrocope to rule out ocular surface and anterior segment abnormalities. The internal structure of the eyes were properly examined with a direct ophthalmoscope to rule out disease of the posterior segment. Blood pressure was measured with a sphygmomanometer to rule out hypertensive patients from the study. Intraocular pressure was measured at baseline (that is before injection of $200 \mathrm{mg}$ of noresthisterone enanthate NET-EN) and at two months after injection of NET-EN at 8.00a.m to 11.00a.m with Perkins Applanation tonometer to minimize the effect of diurnal variation.

\section{Inclusion criteria}

Women of child bearing age, within 20-50years of age who had never use injectable contraceptives or any form of hormonal contraceptives before.

\section{Exclusion criteria}

Women with ocular surface anomalies such as Corneal scar, corneal abrasion, Women that are Hypertensive and over the age of 50 and those who were already on contraceptives

\section{Intraocular pressure measurement}

The tonometer prism was disinfected for 5 minutes using methylated spirit. It was rinsed with distilled water and after that, it was dried using cotton wool, then the prism was inserted into the tonometer bracket holder, ensuring the $0^{\circ}$ or $180^{\circ}$ markings line dull up with the white marker point of the tonometer head. Both eyes were anaesthetized with $0.5 \%$ proparacaine hydrochloride with the subject sitting down. Fluorescein paper strip was placed in the outer canthus in the lower conjunctival sac a minute after anaesthetizing the eyes. The patient was told to close their eyes briefly before taking the measurement for the corneal to be sufficiently moist with the lacrimal fluid and fluorescein. The blue filter was selected on the tonometer, the tonometer was turned on and calibrated dial was adjusted to a value of $10 \mathrm{mmHg}$. With the patient looking at the fixation light, the tonometer was moved towards the patient's eye until tip of the bi-prism contacts the centre of cornea. After contact, visible semi circles appeared through the eyepiece. The calibrated dial was adjusted until inner edges of the upper and lower semi-circle were aligned. After this, the intraocular pressure was then measured and noted

\section{Statistical analysis}

Data obtained were analysed using paired t-test and the descriptive statistic with the aid of statistical package for Social science (SPSS Version 22.0).

\section{RESULTS}

The 85 subjects enrolled in this study were grouped into two age groups (Table 1).

Table 1: Distribution of the age groups.

\begin{tabular}{|lll|}
\hline Age (years) & Frequency & Percent \\
\hline $\mathbf{2 0}-\mathbf{3 5}$ & 50 & 58.8 \\
\hline $\mathbf{3 6}$ - 50 & 35 & 41.2 \\
\hline Total & 85 & 100.0 \\
\hline
\end{tabular}


Majority of the women were between the ages of 20-35 $(58.8 \%)$. A descriptive statistic was performed on the IOP reading derived from the women (Table 2 ).

There was a slight increase in IOP in Age group 20-35 $(0.04 \mathrm{mmHg})$ at baseline and after two months of injectable contraceptives, which was not statistically significant $(\mathrm{p}>0.05)$.

However, a decrease in IOPs reading was observed in age groups $36-50 \quad(-0.43 \mathrm{mmHg})$ which was statistically significant $(\mathrm{p}<0.05)$.

Table 2: Descriptive statistics of the IOPs based on the age groups.

\begin{tabular}{|lllll|}
\hline Age range & Mean age (years) & Baseline IOP $(\mathrm{mmHg})$ & $\begin{array}{l}\text { IOP }(\mathrm{mmHg}) \text { two months after } \\
\text { injection of contraceptives }\end{array}$ & P-value \\
\hline $\mathbf{2 0 - 3 5}$ & $29.66 \pm 3.43$ & $14.82 \pm 2.20$ & $14.86 \pm 2.195$ & 0.819 \\
\hline $\mathbf{3 6 - 5 0}$ & $40.63 \pm 4.41$ & $15.66 \pm 2.59$ & $15.23 \pm 2.67$ & 0.049 \\
\hline
\end{tabular}

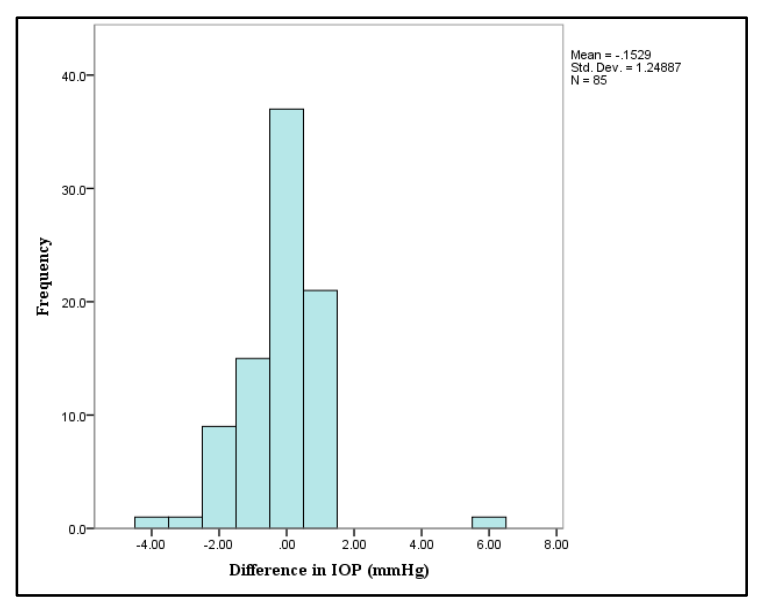

Figure 1: Frequency distribution of the difference between IOP reading 2 months after ingestion of contraceptive and the baseline IOP.

The mean difference was $-0.15 \pm 1.25 \mathrm{mmHg}$. A comparison of both readings (i.e. the baseline IOP and the IOP after the injection of contraceptives) with the paired-sample $\mathrm{T}$ test revealed that there was no statistically significant difference between the readings $(\mathrm{p}=0.262)$.

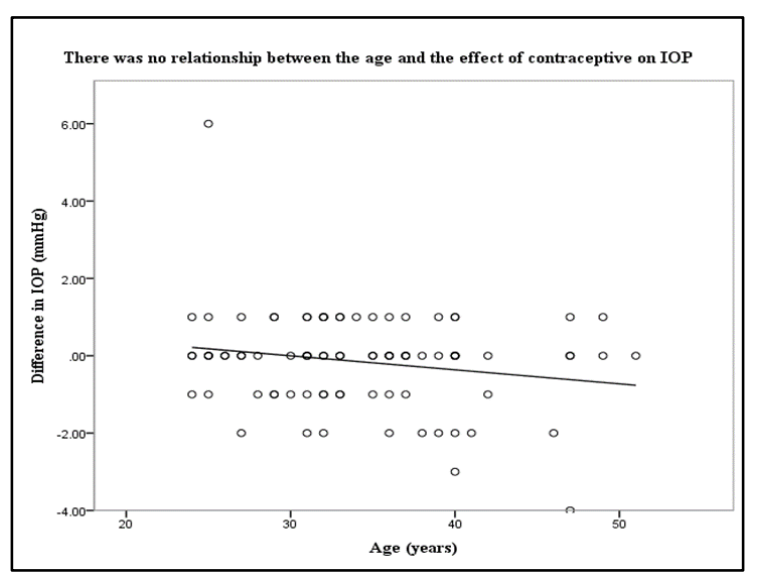

Figure 2: The association between the age of the individuals and the effect of contraceptive i.e. the difference in the IOP after 2 months.
There was no association between age and the effect of contraceptive injection on IOP $(r=0.10, p=0.362)$

\section{DISCUSSION}

Intraocular pressure (IOP) is essential in maintaining normal function of the eye. Elevated IOP is associated with glaucoma. Many physiological factors, including age and hormones, can cause variation in IOP. The result from our study showed a statistically significant reduction in IOP after 2 months of injectable contraceptives amongst women aged 36-50. This was similar to the work done by Thasarat et al where a significant reduction in intraocular pressure was noticed among women (50-79) who were treated with estrogen. ${ }^{16}$ A similar study was conducted among women 40-50 years and a reduction in intraocular pressure was found $\mathrm{p}<0.05$ after two months. ${ }^{17}$ This decrease could be due to decreased retinal ganglion cell and axon loss through inhibition of ganglion cell apoptosis. This is because hormone receptor are expressed in a variety of ocular tissue including retinal ganglion cells, lens epithelial cells, corneal epithelium, ciliary body and iris stoma. ${ }^{18} \mathrm{It}$ could also be due to the fact that this hormone enhances nitric oxide signalling within the trabecular meshwork and in the retinal vasculature that supplies the optic nerve to favourably modify outflow facility and retinal auto regulation respectively thereby reducing the susceptibility to increased intraocular pressure. ${ }^{19}$

The anti-glucocorticoid properties of progesterone may have role in the reduction of IOP in women on injectable contraceptives. Endogenous corticosteroids have ocular hypertensive effect and progesterone inhibits this effect. 20 this has been reported in a study were the use of Hormonal replacement therapy in post-menopausal women caused a reduction in IOP. ${ }^{20} \mathrm{~A}$ slight increase in intraocular pressure was observed for the 20-35 years of age group but this increase was not statically significant. This is consistent with the work done by pasquale et al. where a moderately increased risk of primary open angle glaucoma was found in women using contraceptive. ${ }^{21}$

In overall, injectable hormonal contraceptives causes a significant reduction in IOP among women of child 
bearing age. However, further studies may be required to investigate the long term effect of hormonal contraceptives on IOP among women. Injectable hormonal contraceptive have a significant effect on intraocular pressure mostly among women 36-50 years. However a slight increase in intraocular pressure was noticed among younger women 20-35, the eyes of these women should be monitored closely with regular intraocular pressure measurement. Women within age group 20-35 years who wants to use contraceptives should be monitored frequently by Optometrists for changes in their IOP. Further studies involving a larger sample should be conducted over a long duration in order to achieve a better generalization of the findings on this subject matter.

\section{CONCLUSION}

Injectable contraceptives have significant effect on IOP of healthy women of childbearing age. Further studies involving a larger sample should be conducted over a long duration in order to achieve a better generalization of the findings on this subject matter.

\section{ACKNOWLEDGMENTS}

Authors would like to thank individuals who participated in the study.

Funding: No funding sources

Conflict of interest: None declared

Ethical approval: The study was approved by the Institutional Ethics Committee

\section{REFERENCES}

1. Rocha EM, Wickham LA, Silveira LA. Identification of androgen receptor protein and 5 a-reducase mRNA in humanocular tissues. Br J Opthalmol. 2000;84:76-8.

2. Ebeigbe J. Sex hormone levels and intraocular pressure in postmenopausal Nigeria women. Afr J Med Sci. 2013;42(4):317-23.

3. Nuzzi R, Scalabrin S, Becco A, Panzica G. Gonadal hormones and retinal disorders: a review. Front Endocrinol. 2018;9:66.

4. Perogamvros GI, Ray DW, Trainer PJ. Regulation of cortisol bioavailability-effects on hormone measurement and action. Nat Rev Endocrinol. 2012;8(12):717-27.

5. Snow R, Garcia S, Kureshy N. Attributes of contraceptive technology: women's preference in seven countries. Beyond acceptability: users perspective on contraception. Reprod Health Matters. 1997:36-48.
6. Sator MO, Joura EA, Frigo P. Hormone replacement therapy and intraocular pressure. Maturitas. 1997;28:55-8.

7. Affinito P, Sardo AS, Carlo DC. Effects of hormone replacement therapy on ocular function in postmenopause. Menopause. 2003;10:482-7.

8. Altintas O, Caglar Y, Yuksel N. The effects of menopause and hormone replacement therapy on quality and quantity of tear, intraocular pressure and ocular blood flow. Ophthalmologica. 2004;18:120-9.

9. Uncu G, Avci R, Uncu Y. The effects of different hormone replacement therapy regimens on tear function, intraocular pressure and lens opacity. Gynecol Endocrincol. 2006;22:501-5.

10. Vajaranant TS, Maki PM, Pasquale LR. Effects of hormone therapy on intraocular pressure: the Women's Health Initiative Sight Exam Study. Am J Ophthalmol. 2016;165:115-24.

11. Saylik M, Saylik SA. Not only pregnancy but also the number of fetuses in the uterus affects intraocular pressure. Indian J Ophthalmol. 2014;62:680-2.

12. Green K, Phillips CI, Cheeks L. Aqueous humor flow rate and intraocular pressure during and after pregnancy. Ophthalmic Res. 1988;20:353-7.

13. Wilke K. Episcleral venous pressure and pregnancy. Acta Ophthalmol Suppl. 1975;125:40-1.

14. Ofri R, Shore LS, Kass PH. The effect of elevated progesterone levels on intraocular pressure in lions (Panthera leo). Res Vet Sci. 1999;67:121-3.

15. Lin S, Wang E, Kakigi C. Oral contraceptive use and prevalence of self-reported glaucoma or ocular hypertension in the United States. J Ophthalmol. 2016;123(4):729-36.

16. Thasarat V, Maki P, Pasquale L, Lee A, Hajwa K, Haan M. Effect of hormone therapy on intraocular pressure. Am J Ophthalmol. 2016;165:115-24.

17. Altintas O, Caglar Y, Yuksel N, Demirei A, Karabas L. The effect of menopause and hormone replacement therapy on quality and quantity of tear, inttraocular pressure and ocular blood flow. Int J Ophthalmol. 2004;218:120-9.

18. Lin S, Wang E, Kakigi C. Oral contraceptive use and prevalence of self-reported glaucoma or ocular hypertension in the United States. J Ophthalmol. 2016;123(4):729-36.

19. Qureshi I. A intraocular pressure: association with menstrual cycle, pregnancy and menopause in apparently healthy women. Chin J Physiol. 1995;38:229-34.

20. Sait CO, Harun ET, Deniz O, Faith MA, Nese GH, Korhan K. Does HRT change intraocular pressure in post- menopausal women. Eastern J Med. 2017;2(2)536.

21. Pasquele LR, Kang JH. Female reproductive factors and primary open angle glaucoma in the Nurse Health Study. Eye Journal. 2011;25(5):633-41.

Cite this article as: Uwagboe PN, Uwagboe CU, Mba CR. Effects of injectable contraceptives on intraocular pressure among women of child bearing age. Int J Reprod Contracept Obstet Gynecol 2021;10:444-7. 